\title{
Educação no campo, mulheres e movimentos sociais: espaços de vida, ensinamentos para a transformação social brasileira
}

\author{
Educação, relações de gênero e \\ movimentos sociais: um diálogo \\ necessário.
}

MENEGAT, Alzira Salete; TEDESCHI, Losandro Antonio; FARIAS, Marisa de Fátima Lomba de (Org.).

Dourados: UFGD, 2009. $278 \mathrm{p}$.

Interdisciplinar. Essa é a palavra-chave de Educação, relações de gênero e movimentos sociais: um diálogo necessário, organizado pelas sociólogas Alzira Salete Menegat e Marisa de Fátima Lomba de Farias e pelo historiador Losandro Antonio Tedeschi. A presente obra é composta de 11 artigos e articulada pelas falas da Sociologia, da História, da Filosofia, do Direito e da Pedagogia, no intuito de criar um diálogo sobre "[...] os conflitos próprios da condição humana frente a uma sociedade orientada por princípios competitivos e por interferência reificadora da mercadoria das relações sociais" (p. 11).

Nessa tentativa de religar as ciências e criar um espaço de debate, a obra elege três grandes eixos - Educação, Relações de gênero e Movimentos sociais - para discutir a temática do campo/rural. A escolha de tais eixos foi realizada a partir da prática do trabalho acadêmico, através da criação do curso de licenciatura em Ciências Sociais, do Programa Nacional de Educação na Reforma Agrária Pronera, da Universidade Federal da Grande Dourados - UFGD, cuja existência se deve a um esforço coletivo entre a UFGD, o Instituto Nacional de Colonização e Reforma Agrária - Incra e diversos segmentos dos movimentos sociais rurais de Mato Grosso do Sul. É, portanto, uma obra comprometida com a reflexão de experiências práticas e uma tentativa de diálogo a respeito das pesquisas e práticas educativas que se desenvolvem no referido curso.

O livro é dividido em duas partes: priorizase, na primeira, a questão da educação no campo/rural e, na segunda parte, a análise recai basicamente na temática de gênero e suas interfaces nos movimentos sociais.

A primeira parte, "Educação, educação do campo: interfaces de uma proposta emancipadora", é composta de cinco artigos que buscam articular o esforço reflexivo de reconhecimento e melhorias nas estruturas locais como, por exemplo, a melhoria no acesso e na qualidade da educação no campo, tópico considerado fundamental para os autores.

A educação no campo surge no capítulo de Cecília Maria Ghedini a partir do estudo das relações dos sujeitos históricos - os camponeses - com a educação, bem como das relações históricas constituídas na proposta de educação no campo. É interessante observar que o Campo é pensado como um espaço de vida em todas as articulações e complexidades, e não apenas como um espaço de produção externa.

Em "Desenvolvimento e educação do campo em construção: referenciais teóricometodológicos", a pedagoga Solange Todero Von Onçay analisa as resistências, os questionamentos e as conquistas dos movimentos sociais rurais a partir da experiência do Projeto Vida na Roça - PVR, realizado no município de Dois Vizinhos, no Paraná. Ao traçar um panorama histórico dos modelos de desenvolvimento econômico rural brasileiro, Onçay procura compreender de que maneira 0 projeto influenciou na modificação do entendimento dos sujeitos sociais a respeito do próprio viver no campo. A partir dos pressupostos colocados por Paulo Freire, a autora empreende uma defesa apaixonada pela necessidade de um engajamento educacional no campo como 
forma de superação das desigualdades historicamente construídas.

Democratizar o poder, construir hegemonia popular, sacudir o imobilismo, superar a impotência criada por práticas clientelistas e fragmentadas, tão comumente usadas na política, assim como canalizar e focalizar esforços em nome de um projeto coletivo e, acima de tudo, permitir que os próprios sujeitos comandem o processo, a partir de suas escolhas conjuntas, tem sido a metodologia potencializadora do PVR (p. 55).

Em seguida, o professor Walter Roberto Marschner propõe uma reflexão teórica a respeito das noções de rural e urbano tal como são compreendidas pelas Ciências Sociais e seus possíveis significados em diferentes contextos históricos na sociedade ocidental. A compreensão das complexidades de tais conceitos serve de ponto de partida para uma reflexão das noções de sociedades camponesas e reforma agrária. O autor afirma que $o$ contraste do urbano $x$ rural residiria num primeiro momento na necessidade do estabelecimento de uma distinção identitária de oposição, mas que é possível o desenvolvimento de discursos e representações desses espaços que apontem para convergências entre a cidade e o campo, o que traria novas perspectivas de socialização.

No quarto capítulo do livro, "Docência universitária: ensino, pesquisa e extensão tendo como eixo o desenvolvimento de comunidades de aprendizagem em escolas públicas brasileiras", a noção de trabalho conjunto transparece na autoria coletiva da professora Roseli Rodrigues Mello com mais cinco autores/ as. O artigo traz um balanço do projeto desenvolvido pela Universidade Federal de São Carlos - UFSCAR com financiamento da Fundação de Amparo à Pesquisa do Estado de São Paulo - Fapesp e do CNPq, através do Núcleo de Investigação e Ação Social e Educativa - Niase, que busca atuar nas escolas municipais da cidade de São Carlos através de propostas que congreguem os princípios de solidariedade, a partir do conceito de aprendizagem dialógica, que compreende os princípios de diálogo igualitário, criação de sentido e transformação como uma alternativa à estruturação do conhecimento, que, nos tempos da sociedade da informação, tende a individualizar e fragmentar as relações humanas. O projeto de extensão Comunidades de Aprendizagem descrito no texto mostra-se como uma experiência prática da absoluta necessidade de articulação das dimensões de pesquisa, ensino e extensão nos diversos âmbitos da educação.

A primeira parte termina com o artigo "Desenvolvimento local em contexto rural: representações, práticas e contradições", vindo do outro lado do Atlântico. Fernando llídio Ferreira da Universidade do Minho, Portugal, expõe o resultado de uma investigação a partir de dois tipos de dinâmicas empreendidas no município rural do norte de Portugal chamado Paredes de Coura: a primeira desenvolvida na área da educação e a segunda como ação social e comunitária. $O$ interesse do autor reside no estudo das representações construídas a respeito do desenvolvimento local e do mundo rural como orientadores estruturantes das noções sobre o universo rural atribuídas tanto pelos atores sociais quanto pelos pesquisadores envolvidos nos relatórios dos estudos analisados.

A segunda parte, composta de seis artigos, preocupou-se com a articulação entre as rupturas possíveis no que tange a um entendimento mais amplo entre as relações de gênero no bojo dos movimentos sociais no campo. O uso da categoria "gênero" centrouse prioritariamente na figura feminina e na necessidade de uma diferenciação e visibilidade das mulheres e suas demandas no campo. O espaço dos movimentos sociais surge então como lugar privilegiado para uma tomada de consciência de sua importância e do exercício de seus poderes como parte de uma comunidade cuja marca histórica prioriza o trabalho iminentemente masculino.

O professor e doutor em História Losandro Antonio Tedeschi traça um panorama dos papéis e espaços comumente instituídos às mulheres camponesas e ressalta os mecanismos de reprodução das desigualdades de gênero, destacando a importância da incorporação dessa categoria de análise para os estudos sobre as mulheres agricultoras.

Esta se constituiu em uma das formas de excluir as mulheres do espaço público, desqualificando sua força de trabalho, atribuindo-lhes um significado secundário, inibindo sua presença na esfera extradoméstica. Esta desqualificação trazia uma conotação de inferioridade e segregação social, cultural e econômica, sugerindo que, de certa forma, as mulheres agricultoras não possuíam condições de realizar trabalho produtivo [...] O lugar socialmente destinado às mulheres agricultoras continua sendo a família: é na privacidade do lar que, 
prioritariamente, elas encontram a realização pessoal (p. 165).

Essa invisibilidade é uma das características que tal coletânea visa desmistificar, situando o trabalho feminino como parte fundamental, muita vezes até prioritária, para as relações produtivas no campo.

Simone Becker, professora e coordenadora do curso de Direito da UFGD, apresenta um ensaio realizado a partir de documentos coletados na pesquisa entre a Universidade Federal da Grande Dourados e o Incra, cujo objetivo era identificar e delimitar as terras quilombolas em Mato Grosso do Sul. Os poderes e as resistências das mulheres expressos nos documentos encontrados demonstram como o aprofundamento das investigações históricas tende a visibilizar a participação feminina nas esferas econômicas e sociais, auxiliando no rompimento de uma concepção de história marcada pelo binômio homem dominante $\mathrm{x}$ mulher submissa.

Em "Ambiguidades na vida das famílias nos espaços de reforma agrária", Giana Amaral Yamin da Universidade Estadual de Mato Grosso do Sul e Marisa de Fátima Lomba de Farias da UFGD analisam as ambiguidades nos discursos e nas práticas das famílias assentadas em Mato Grosso do Sul. As memórias das famílias assentadas reconstroem de modo particular os sentidos de reforma agrária orientados pelo imaginário de terra da fartura, cujo convívio choca-se com os desafios empreendidos na realidade assentada.

Ainda na temática dos assentamentos está o artigo da socióloga Alzira Salete Menegat, "Mulheres assentadas abrem novas portas. Quais Portas?", cujas reflexões partem das observações sobre as vidas das mulheres dos lotes de Taquaral e Rio Bonito. O entendimento da dinâmica e dos espaços sociais ocupados pelas mulheres assentadas procura salientar o processo de empoderamento feminino a partir das múltiplas situações vividas, dificuldades e transformações experienciadas.

A violência de gênero aparece no artigo do professor André Luiz Faisting, situando a efetividade da Lei Maria da Penha no contexto rural contemporâneo, bem como no processo de entendimento da violência de gênero como uma violação aos direitos humanos da mulher. O autor ressalta que um dos grandes desafios brasileiros está no estabelecimento efetivo de uma educação voltada para a valorização dos direitos humanos, pois, embora o Brasil tenha sido um dos primeiros países a adotarem as recomendações da Conferência Mundial de Viena (1933), apenas em 2006 a Lei Maria da Penha foi promulgada.

As impressões analíticas sobre as condições de vida, as práticas sociais, as formas de resistência e os micropoderes exercidos pelas mulheres no campo são os pontos de conexão entre os artigos, revelando um vasto campo de investigação das Ciências Humanas a respeito da realidade rural no Brasil.

Muito embora o artigo de autoria de Gaby Cevasco aborde a realidade do feminismo e dos movimentos sociais no Peru, é possível perceber as diferenças e as semelhanças em relação aos preconceitos sofridos pelas mulheres e suas lutas, pela própria organização da estrutura do livro, que, ao deixá-lo como último artigo, permite ao leitor uma reflexão comparativa entre as realidades brasileiras apresentadas nos primeiros capítulos desta segunda parte.

A obra expressa um processo pedagógico: construção, reflexão e espaço de debate para novas construções. Seus artigos são altamente comprometidos com a dimensão de ações positivas, no sentido de um empoderamento do espaço campo/rural e seus sujeitos sociais. A articulação entre a teoria e a prática aparece no compromisso e no envolvimento com a formação de educadores voltados para o espaço dos assentamentos rurais e a população do campo no Brasil. É, portanto, um grande esforço coletivo fruto de uma sensibilidade acadêmica que busca o equilíbrio entre o saber científico e o saber fazer.

Ana Carolina Eiras Coelho Soares Universidade Federal de Goiás 